\title{
Identification of the Magnetic Poles on Strong Magnetic Grains from Meteorites Using Magnetotactic Bacteria
}

\author{
M. FUNAKI ${ }^{1}$, H. SAKAI ${ }^{2}$, and T. MATSUNAGA ${ }^{3}$ \\ ${ }^{1}$ National Institute of Polar Research, 9-10 Kaga 1-chome, Itabashi-ku, Tokyo 173, Japan \\ ${ }^{2}$ Department of Earth Sciences, Faculty of Sciences, Toyama University, \\ Gofuku, Toyama 390, Japan \\ ${ }^{3}$ Department of Applied Chemistry for Resources, Tokyo University of Agriculture and Technology, \\ Koganei, Tokyo 184, Japan
}

(Received March 5, 1988; Revised June 24, 1988)

\begin{abstract}
Magnetotactic bacteria (north seeking bacteria) have been used to identify the magnetic S pole of iron-nickel grains selected from St. Séverin LL6 chondrite. The results indicate that the bacteria are sensitive magnetic sensors which can be used to detect not only the $\mathrm{S}$ pole in the grains but also the directions of lines of magnetic force radiated from the grains. The magnetic coercive force and the stability of natural remanent magnetization can also be measured with the bacteria by applying a steady magnetic field. These methods can in principle be applied to terrestrial rocks having relatively strong natural remanent magnetization. Thus, the magnetotactic bacteria can give useful information for rock magnetism and paleomagnetism as a bio-magnetometer.

Combining the method of south seeking bacteria and Bitter pattern analyses using colloidal magnetite particles, complex magnetization structures on the surface of $\mathrm{Fe}-\mathrm{Ni}$ grains from the $\mathrm{St}$. Séverin meteorite have been revealed, which is important for an understanding the chondrite magnetism.
\end{abstract}

\section{Introduction}

The natural remanent magnetization (NRM) of rocks is measured using astatic, spinner or SQUID magnetometers. The NRM is a value of integrated NRMs of individual magnetic grains in a rock sample. Although the Bitter pattern configurations using magnetite colloidal suspension liquid indicate the presence of magnetic minerals in terrestrial rocks (WASILEWSKI and CARLETON, 1967) and strong NRM areas and magnetic domain structures such as in the Bocaiuva iron meteorite (FUNAKI et al., 1988), the magnetic polarity cannot be determined by this method. The identification of the magnetic polarity of magnetic grains can give useful information not only for rock magnetism but also for archeomagnetism and paleomagnetism. We have attempted a new technique for identification of the magnetic polarity of magnetic grains and the directions of the lines of magnetic force radiated from those grains, using characteristics of magnetotactic bacteria.

In this paper we describe an application of magnetotactic bacteria in order to 
identify the magnetic south pole of two selected iron-nickel grains from St. Séverin LL6 chondrite. The magnetotactic bacteria were cultivated by the method of MATSUNAGA and KAMIYA (1987).

BLAKEMORE (1975) first described magnetotactic bacteria which swim toward preferable south or north directions along even a weak $(10 \mu \mathrm{T})$ geomagnetic field. The bacteria in the northern hemisphere characteristically swim toward the $\mathrm{S}$ pole (north seeking bacteria), whereas in the southern hemisphere the bacteria swim toward the $\mathrm{N}$ pole (south seeking bacteria). In the geomagnetic equator region, the existence of both north and the south seeking bacteria has been confirmed (FRANKEL et al., 1981). The magnetotactic microorganisms contain single domain magnetite, $100-150 \mathrm{~nm}$ in size, aligned in rows of 10-20 grains (KALMIJN and BLAKEMORE, 1978; TORRES DE ARAUJO et al., 1986; ESQUIVEL and LIN DE BARROS, 1986) which constitute a navigation compass. Magnetotactic microorganisms have been found not only in freshwater but also in saltmarsh sediments (KALMIJN and BLAKEMORE, 1978).

2. Basic Magnetic Properties of Separated Magnetic Grains from the St. Séverin Chondrite

Usually the preparation of pure magnetic grains holding the original grain shape from a terrestrial rock is very difficult due to their brittle properties. We used in the present work samples which include strong NRM grains, such as the $\mathrm{Fe}-\mathrm{Ni}$ grains from the St. Séverin meteorite.

The St. Séverin is an LL6 chondrite which was studied magnetically by NAGATA et al. (1986). The results showed that the NRM, $10^{-4} \mathrm{Am}^{2} / \mathrm{kg}$, is fairly stable against AF demagnetization supported by extremely high coercive force $\left(H_{\mathrm{C}}=52 \mathrm{mT}\right)$ and remanence coercive force $\left(H_{\mathrm{RC}}=184 \mathrm{mT}\right)$. After heat treatment up to $600^{\circ} \mathrm{C}, H_{\mathrm{C}}$ and $H_{\mathrm{RC}}$ decrease to much smaller values. In order to separate the magnetic grains from St. Séverin, the meteorite was gently crushed in an agate mortar. Magnetic hysteresis of the separated $\mathrm{Fe}-\mathrm{Ni}$ grains were measured at room temperature from -1.4 to $+1.4 \mathrm{~T}$ and the thermomagnetic properties were determined. The hysteresis characteristics, as shown in Table 1, are consistent with the values reported by NAGATA et al. (1986). The thermomagnetic curve of the $\mathrm{Fe}-\mathrm{Ni}$ grains exhibits a small change in the magnetization from room temperature up to $500^{\circ} \mathrm{C}$, then decreases abruptly at $560^{\circ}$ and $765^{\circ} \mathrm{C}$, as shown in Fig. 1. This magnetic behavior indicates the presence of the ordered $50-50 \mathrm{Fe}-\mathrm{Ni}$ alloys

Table 1. Magnetic hysteresis data of the Fe-Ni grains selected from St. Séverin meteorite.

\begin{tabular}{lcccr}
\hline Condition of sample & $I_{\mathrm{S}}$ & $I_{\mathrm{R}}$ & $\boldsymbol{H}_{\mathrm{C}}$ & $\boldsymbol{H}_{\mathrm{RC}}$ \\
\hline Original sample & 81 & 23.5 & 76.5 & 147.7 \\
After heating to $800^{\circ} \mathrm{C}$ & 116 & 0.40 & 0.35 & 6.0 \\
\hline Unit & $\mathrm{Am}^{2} / \mathrm{kg}$ & $\mathrm{Am}^{2} / \mathrm{kg}$ & $\mathrm{mT}$ & $\mathrm{mT}$ \\
\hline
\end{tabular}




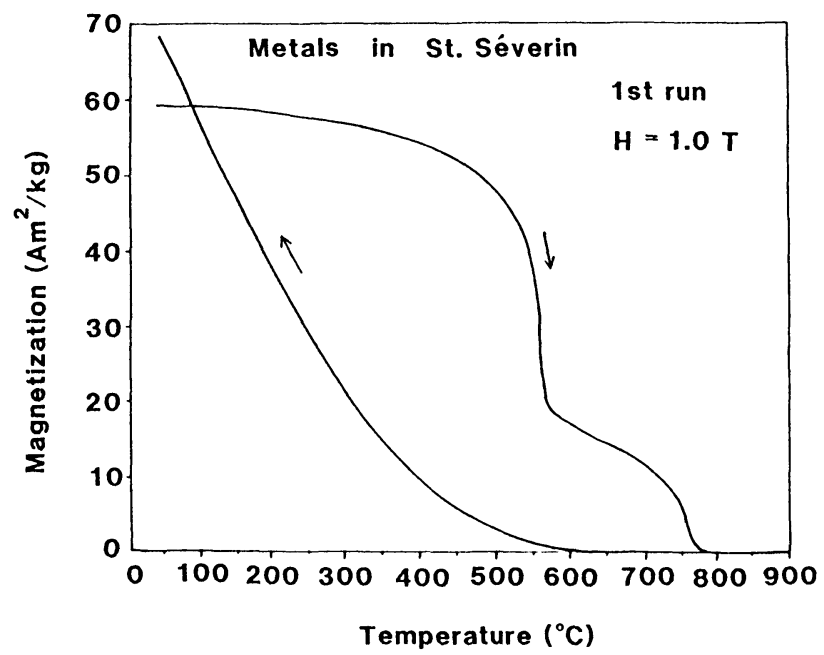

Fig. 1. Thermomagnetic curve of 1 st run cycle under $1 \mathrm{~T}$ of applied magnetic field for iron-nickel grains selected from the St. Séverin chondrite.

tetrataenite (CLARKE and SCOTT, 1980) and kamacite, respectively, as the main magnetic minerals in the $\mathrm{Fe}-\mathrm{Ni}$ grains. The existence of kamacite, taenite and tetrataenite in the St. Séverin was previously reported from Mössbauer spectroscopy measurements (DANON et al., 1979).

\section{Microscopic Observations and Bitter Pattern Configurations on the Grains}

Relatively large $\mathrm{Fe}-\mathrm{Ni}$ grains (more than $0.5 \mathrm{~mm}$ in diameter) were selected and fixed on a glass slide by a nonmagnetic transparent resin and subsequently polished with diamond paste. Among these polished grains, two samples of $\mathrm{Fe}-\mathrm{Ni}, 0.68 \times 0.96$ $\mathrm{mm}$ (sample A) and $0.71 \times 1.25 \mathrm{~mm}$ in size (sample B) with thickness of $0.2 \mathrm{~mm}$ were prepared for the microscopic observations. The samples were etched slightly with nitric acid solution in order to reveal the surface structures, which were observed under a reflected light microscope. Sample A consisted of taenite for almost all areas, associated with minor amounts of kamacite at the top and at the bottom of the sample, as shown in Fig. 2. The main part of the surface of sample B was composed of taenite associated with kamacite which appeared across the center and the lower left side of the sample (Fig. 4).

Subsequently, samples A and B were painted with magnetic fluid (Bitter pattern analysis) in order to find dense concentration regions of magnetic particles on their surfaces. The magnetite particles in the fluid are between about 50 and $100 \AA$ in diameter, with superparamagnetic behaviour. The magnetic fluid concentrates only on strong NRM regions such as domain walls, etc., which overcome the Brownian motion of the particles. The results for sample A indicated strong NRM limbs of the 


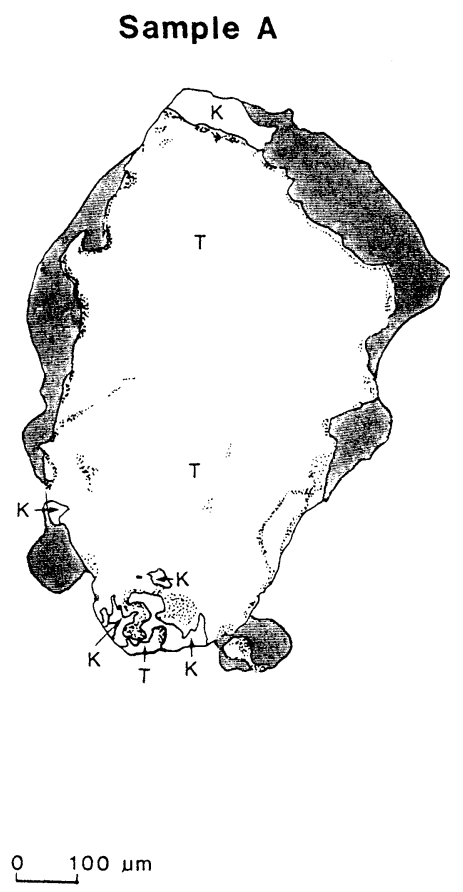

Fig. 2. Structures and concentration regions of the magnetic fluid for sample A. K: kamacite, T: taenite, dotted area: concentration region of magnetic fluid, shadow area: nonvisible area under the transparent light microscope.

grain and relatively strong ones inside the sample, as shown in Fig. 2. At the bottom of the sample, the fluid concentrated along the boundary of kamacite with taenite, forming a complicated distribution. On the other hand, the surface of grain B shows that the strong NRM regions were mainly formed inside the grain, across the center and at the left side of its lower half. Relatively strong regions were also formed in some parts of the grain limb. These features of the dense concentration (strong NRM) regions are similar to those of the tetrataenite phase observed in the Bocaiuva meteorite as reported by FUNAKI et al. (1988).

\section{Trails and Swarming Regions of Magnetotactic Bacteria}

The directions of the line of magnetic force resulting from the S pole of sample A were identified using north seeking bacteria under a transparent light microscope. The geomagnetic field acting condition around the microscope was $41.9 \mu \mathrm{T}$ of the total intensity, $22.0 \mu \mathrm{T}$ of the horizontal component and $58.3^{\circ}$ in inclination. The sample was placed on the stage of the microscope, and then a drop of water containing a large number of magnetotactic bacteria, 1-2 $\mu \mathrm{m}$ in diameter, was 


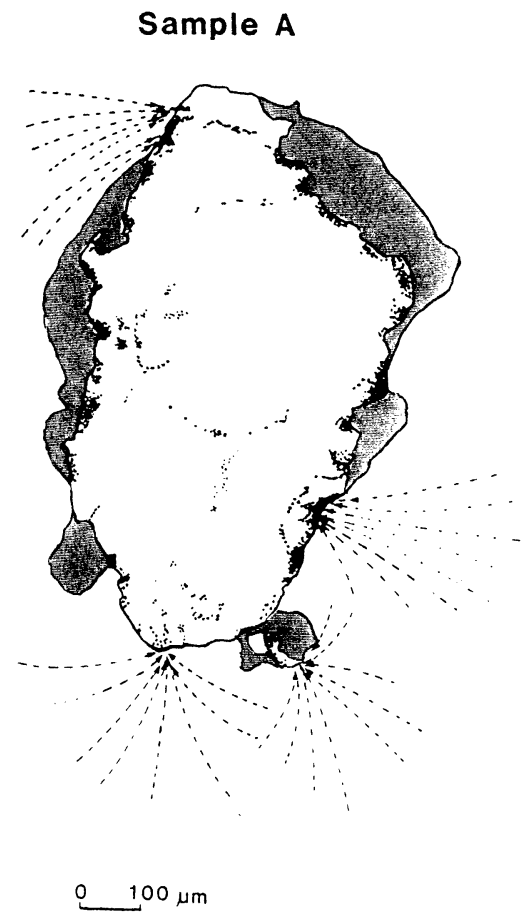

Fig. 3. Trails (perforated line) and swarming regions (dotted area) of the north seeking bacteria of sample A.

spilled on it. Subsequently, a cover glass was placed on the sample in order to adjust its focus. The trails of the bacteria were recorded on videotape within 1 minute of the spilling.

The trails and swarming regions of the bacteria were clearly identified around the edge of sample A, except in a shadowed area which is not visible under the transparent light microscope, as is illustrated in Fig. 2. The bacteria already clearly swarmed to 4 regions within 1 minute of the spilling. The bacteria gathered in those sites, describing trails of parabolic loci with roughly $25-75 \mu \mathrm{m} / \mathrm{s}$ in speed. In general, the swimming speed of bacteria around the samples was faster at the beginning and slower in the following stage. The speed of the individual bacteria is approximately constant and every bacteria swam with zigzag motions of several microns in amplitude.

When an $\mathrm{N}$ pole radiated from a samarium-cobalt hand magnet gradually approached gradually to within $20 \mathrm{~cm}$ of sample A, the swarming areas were expanded gradually and swimming bacteria on the way made U-turns. The magnetic field intensity was estimated to be about $0.25 \mathrm{mT}$ when the magnet was at a distance of $20 \mathrm{~cm}$. The swarms oscillated synchronously with the movements of the magnet. 


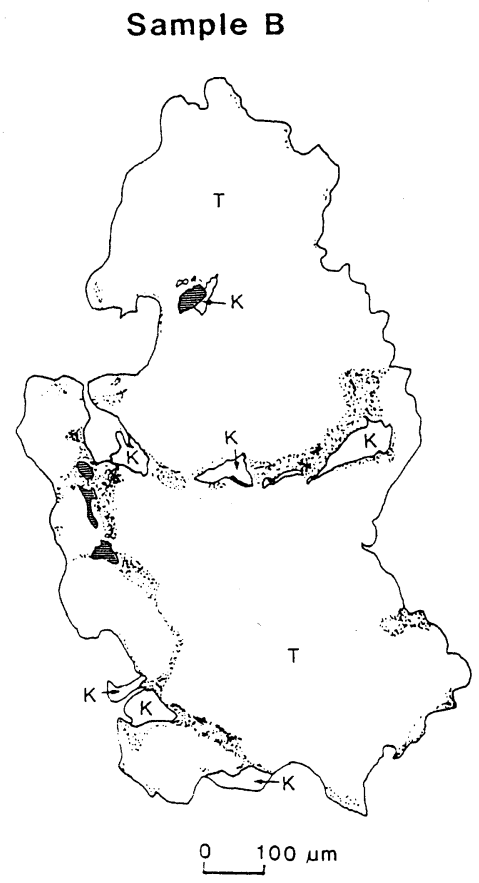

Fig. 4. Structures and concentration regions of the magnetic fluid for sample B. K: kamacite, T: taenite, dotted area: concentration region of magnetic fluid, shadowed area: silicate inclusion.

Samples A and B with a large concentration of magnetotactic bacteria were observed by a reflected light microscope under a controled geomagnetic field to 400 nT obtained with a Helmholtz coil. The magnetotactic bacteria did not move towards a given direction in this weak residual magnetic field. The dense swarms of bacteria were clearly recognized within a minute after spilling water, as shown in Fig. 3 for sample A and in Fig. 5 for sample B. Individual bacteria vibrated continuously in the swarms. On sample A, the swarms were formed along limbs of the sample. Dense populations of the bacteria were observed at the regions of convergence of trails. Small unclearly defined swarms were observed with alignment at the inner part. In the case of sample B, relatively dense swarms were observed on the top of the grain, although small swarms were recognized at several regions on the sample and along its limb. At the dense swarming regions on the top of sample $\mathrm{B}$, banded structures of the bacterium alignments were identified.

\section{Discussion}

Large amounts of the tetrataenite phase (more than $40 \mathrm{wt} \%$ ) are present in the metal particles of the St. Séverin chondrite, as has been shown by Mössbauer 


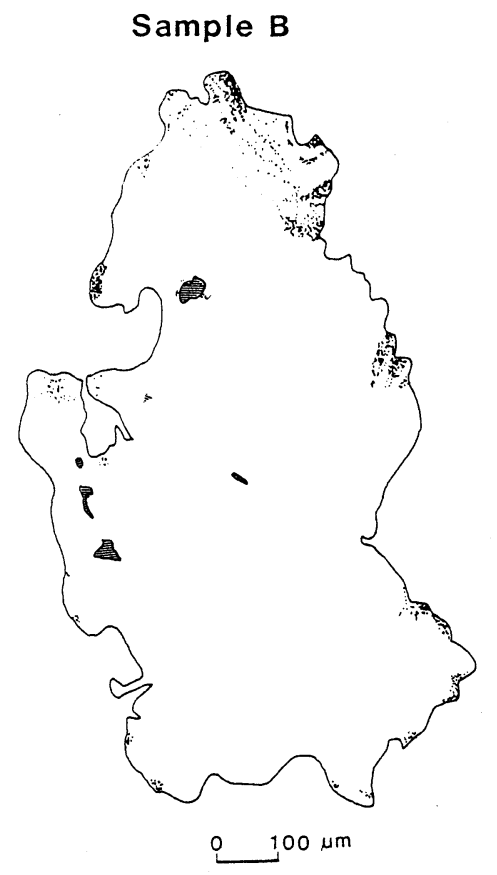

Fig. 5. Swarming regions of the north seeking bacteria of sample B. Shadow area: silicate inclusion.

spectroscopy (DANON et al., 1979) and by magnetic analysis (NAGATA et al., 1986). Selected Fe-Ni grains from the St. Séverin showed typical thermomagnetic curves (Fig. 1) and magnetic hysteresis values (Table 1) of tetrataenite, and samples A and $B$ include in their composition a large fraction of the tetrataenite phase. The NRM intensity of pure tetrataenite phase has been reported by FUNAKI et al. (1986), and is extremely strong $\left(2.58-37.42 \times 10^{-2} \mathrm{Am}^{2} / \mathrm{kg}\right)$. Using the Bitter pattern method, one observes that dense concentrations of the magnetic fluid appears on the tetrataenite phase on samples A and B due to their strong NRM intensities.

Since the north seeking bacteria swim toward the south pole, the swarming regions of bacteria have been magnetized to the $S$ pole. The convergent trails of the bacteria indicate the directions of the line of magnetic force toward the $\mathrm{S}$ pole, because the magnetotactic bacteria swim along the lines of magnetic force, while they are never drawn by the magnetic gradient (BLAKEMORE, 1975).

The experiment was made in a geomagnetic field of $41.9 \mu \mathrm{T}$ in total intensity and $58.3^{\circ}$ in inclination. Since the NRM intensity of the tetrataenite phase is very strong, the magnetic field intensity in the vincinity of the tetrataenite phase is much stronger than the horizontal geomagnetic component $(22.0 \mu \mathrm{T})$, indicating a neglegible influence of the geomagnetic field around the tetrataenite. It is thus 
concluded that the trails indicate the directions of the line of magnetic force resulting from $\mathrm{S}$ pole of sample $\mathrm{A}$. The population of swarming bacteria is probably directly proportional to the density of the magnetic flux.

The magnetic fluid concentrates on the surfaces where the lines of magnetic force leaked out from the sample to the external space. Since the north seeking bacteria gather at the $\mathrm{S}$ poles of the sample, the concentration regions of magnetic fluid where the bacteria do not concentrate probably indicate the $\mathrm{N}$ pole.

In sample $\mathrm{A}$, the configurations of the magnetic fluid concentration regions of (Fig. 2) are in general similar to those obtained with the magnetotactic bacteria (Fig. 3 ). At some regions, however, the swarming bacteria are not clearly concentrated, while concentrations of magnetic fluid are observed. These regions are considered to be magnetized to the $\mathrm{N}$ pole. On the other hand, the swarming bacteria are clearly observed at the bottom of the sample, but the concentration of the magnetic fluid is not apparent. The representative pictures of the magnetic fluid concentration (Fig. 6(a)) and the bacteria swarming (Fig. 6(b)) of sample A indicate the difference of their configurations in detail. Only four divergences of the trail of bacteria were identified in spite of the existence of the swarming bacteria along the major part of the limb for sample A. This suggests that the lines of magnetic force closed within the sample; they do not pass through the outside of the limb.

In the case of sample B, the configurations of both the magnetic fluid (Fig. 4) and the magnetotactic bacteria (Fig. 5) are largely different for the major regions. Detailed structures are shown in Figs. 6(a) and (b). The main swarms of the bacteria appear at the upper part of the sample, while those of the magnetic fluid concentration appear across the center of the sample and at the left side of its lower half. The differences between both configurations can be explained by differences in polarity and intensity of the local magnetization. The differences observed at the upper part of the sample can be explained as follows. The particles in the magnetic fluid are 50-100 $\AA$ in diameter, being superparamagnetic and cannot assume any residual magnetization. When these particles interact with a magnetic field on the sample, they remain on the surface, if the magnetic energy exceeds the Brownian motion. The region at the top of sample $B$ is magnetized to the $S$ pole since it concentrates large numbers of the bacteria, but the Bitter pattern configurations cannot be observed, probably due to the relatively weak NRM intensity at that area (Fig. 4). Magnetic pole identification using the magnetotactic microorganisms thus appears as a more sensitive method when compared to the Bitter pattern method.

Magnetic grains from the St. Séverin meteorite exhibit a very complicated NRM distribution, as is observed with samples A and B. This illustrates the complexity of paleomagnetic analysis for the meteorite, even if it exhibits a stable NRM.

We used only north seeking bacteria in this study and could identify the magnetic structures of the $\mathrm{S}$ pole on the selected tetrataenite grains from the St. Séverin meteorite. The results may have some vagueness due to the lack of $\mathrm{N}$ pole data for the samples, which would require the use of south seeking bacteria found in the southern hemisphere (BLAKEMORE, 1975). 

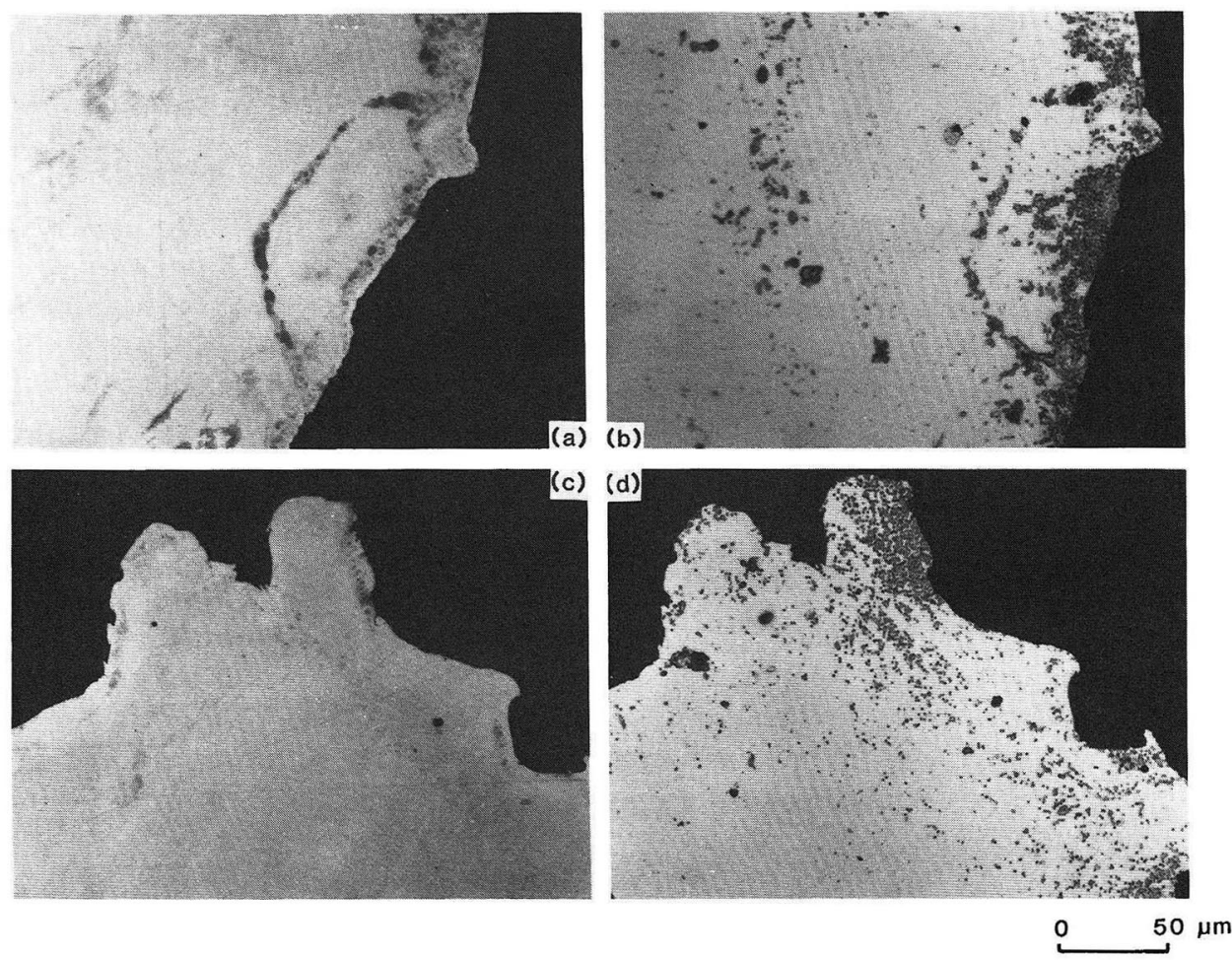

Fig. 6. (a) configuration of magnetic fluid (the Bitter pattern) on the center of right side of sample A. (b) swarming magnetotactic bacteria on the same region of sample A. (c) almost no configuration of magnetic fluid on the top of sample B. (d) swarming magnetotactic bacterias on the same area of sample B.

In the increasing magnetic field of the $\mathrm{N}$ pole to the $\mathrm{S}$ pole in a sample, the swarmed north seeking bacteria scatter along the applied magnetic field, when the field exceeds the magnetic moment radiated from the $\mathrm{S}$ pole. The applied magnetic field, while bacteria are being scattered, indicates the hardness of the NRM of the sample (stability of NRM). By applying this technique to a magnetically saturated sample, the magnetic coercive force and remanence coercive force can in principle be measured.

The magnetic field produced from terrestrial rocks is frequently stronger than the horizontal component of the geomagnetic field, as is observed with Cenozoic basaltic rock mountains. Many magnetic grains in terrestrial rocks radiate lines of magnetic force around their vicinity and the resulting magnetization has been detected by Bitter pattern configurations. Since the bacteria have more sensitive sensors for detection of magnetic fields, as compared with the Bitter method, it is possible in principle to detect the distribution pattern of the $\mathrm{N}$ and the $\mathrm{S}$ poles in the 
grains and radiated lines of magnetic force from terrestial rocks. A new type magnetometer can be used, a bio-magnetometer, which detects not only fine magnetization structures, including magnetic coercive force and remanent coercive force of individual grains, but also the magnetization of the rock samples.

\section{Conclusions}

$\mathrm{Fe}-\mathrm{Ni}$ magnetic grains in the St. Séverin meteorite present strong magnetization and the $\mathrm{S}$ pole distributions exhibit a complicated pattern. The Bitter pattern and the $S$ pole distributions are similar in the case of sample $A$ but are different in the case of sample B. These differences are discussed in terms of different pole magnetization in the grains.

The magnetotactic bacteria are sensitive sensors for detecting not only the magnetic polarities in small magnetic grains but also directions of the line of magnetic force radiated from those grains. Magnetic coercive force and remanence coercive force can in principle be measured using the bacteria, by applying an external magnetic field. This method can be applied to almost all the relatively strong NRM magnetic grains and samples as a bio-magnetometer. The combination of the north and the south seeking bacteria method and the Bitter pattern method may be a very powerful method for analysis of NRM distributions in fine grains under a reflected light microscope.

The authors wish to express their appreciation to T. Nagata (National Institute of Polar Research) and J. Danon (National Observatory, Rio de Janeiro, Brazil) for discussion of the possibility of the bio-magnetometer and to D. Hashimoto (Tokyo University of Agriculture and Technology) for his experimental assistance.

\section{REFERENCES}

Blakemore, R. P., Magnetotactic bacteria, Science, 190, 377-379, 1975.

Clarke, R. S., Jr. and E. R. D. Scott, Tetrataenite-ordered FeNi, a new mineral in meteorites, Am. Mineral., 65, 624-630, 1980.

Danon, J., R. B. Scorzelli, I. Souza Azecedo, and M. Christophe-Michel-Levy, Iron nickel superstructure in metal particles of chondrites, Nature, 281, 469-471, 1979.

Esquivel, D. M. S. and H. G. P. Lins DE BARRos, Motion of magnetotactic microorganisms, J. Exp. Biol., 121, 153-163, 1986.

Frankel, R. B., F. F. Torres de Araujo, D. M. S. Esquivel, and J. Danon, Magnetotactic bacteria at the geomagnetic equator, Science, 212, 1260-1270, 1981 .

Funakı, M., T. NAgATA, and J. Danon, Magnetic properties of lamellar tetrataenite in Toluca iron meteorite, Mem. Natl Inst. Polar Res., Spec. Issue, 41, 382-393, 1986.

Funaki, M., I. Taguchi, J. Danon, T. Nagata, and Y. Kondo, Magnetic and metallographical studies of the Bocaiuva iron meteorite, submitted to Proc. NIPR Symp. Antarctic Meteorite, 1988.

Kalmijn, A. J. and R. P. Blakemore, The magnetic behavior of mud bacteria, in Animal Migration, Navigation and Homing, edited by K. Schmidt-Koenig and W. T. Keeton, pp. 354-355, SpringerVerlag, Berlin, 1978.

Matsunaga, T. and S. KamiYA, Use of magnetic particles isolated from magnetotactic bacteria for enzyme immobilization, Appl. Microbiol. Biotechnol., 26, 328-332, 1987. 
Nagata, T., M. Funaki, and J. A. Danon, Magnetic properties of tetrataenite-rich meteorites II, Mem. Natl Inst. Polar Res., Spec. Issue, 41, 364-381, 1986.

Torres de Araujo, F. F., M. A. Pires, R. B. Frankel, and C. E. M. Bicudo, Magnetite and magnetotaxis in algae, Biophys. J., 50, 375-378, 1986.

WASILEWSKi, P. J. and B. J. CARleton, Insight into the magnetic mineralogy of Antarctic rocks, $J$. Geomag. Geoelct., 19, 195-201, 1967. 